\title{
The significance of energy consumption in environmental impact of rare earth elements recovery from tailings and mining waste
}

\author{
Karolina Kossakowska ${ }^{1, *}$, and Katarzyna Grzesik $^{1}$ \\ ${ }^{1}$ AGH University of Science and Technology Al. Mickiewicza 30, 30-059 Krakow,
}

\begin{abstract}
Rare Earth Elements (REEs) are identified as critical raw materials for the European Union economy. REEs are not currently produced in the EU, while there are several sources not properly addressed. Within the ENVIREE project tailings from New Kankberg (Sweden) and Covas (Portugal) were identified as rich in REEs and chosen for recovery processing. The Life Cycle Assessment (LCA) methodology was used to evaluate the environmental impact of REEs recovery. The aim of this study is the detailed analysis of several scenarios with different electricity production schemes of REE recovery. The study discusses the share of energy use in the overall impact on the environment, taking into account diversification in the electricity production structure among EU countries. The energy use is a significant contributor to the overall environmental impact of studied cases. Its share in the total environmental burden is reaching up to $47 \%$. The results show that applying the average electricity scheme production for Europe may lead to biased LCA results. For the accurate LCA results the local production schemes of energy for certain countries should be chosen.
\end{abstract}

\section{Introduction}

Rare Earth Elements (REE) include 15 lanthanides (La to Lu), scandium and yttrium. They share many chemical and physical properties and they are relatively abundant in the Earth's crust, however usually not concentrated in economically exploitable ores. The REE are essential for a wide range of applications, especially in so called green-technologies: electric vehicles, wind turbines, high strength magnets, catalysts, superconductors etc. $[1,2]$.

While REEs are highly relevant for high-tech industries and products, there is a significant risk of supply, therefore REEs are considered as critical raw materials for EU economy [3]. Rare earth elements are not currently produced in the EU, while there are several REE containing materials still being not properly addressed. The ENVIREE project, funded by the ERA-MIN programme, addresses the exploitation of secondary sources such as tailings and mining waste. Within the project two secondary sources: tailings from New Kankberg (Sweden) and Covas (Portugal) were identified as rich in REEs and chosen for recovery processing.

\footnotetext{
* Corresponding author: kossakowska@agh.edu.pl
} 
Life Cycle Assessment (LCA) is a valuable tool of environmental management. It is a "cradle to grave" approach for identifying and assessing environmental impacts, throughout of a product or a process life cycle. LCA quantifies the relevant emissions and resources consumption and the resulting environmental and health impacts as well as resource depletion issues. The methodology is frequently employed for the developing new products or processes to be sure that innovative products or processes are environmentally feasible and friendly.

The detailed goal and scope of the LCA study for REE recovery was proposed in the work [4], while screening LCA of REE beneficiation step was presented in the study [5]. These studies proved that energy consumption is a significant issue in the overall environmental impact of REE recovery from secondary sources: tailings and mining waste. Therefore the aim of this study is the detailed analysis of several scenarios with different electricity production schemes of REE recovery from tailings in New Kankberg and mining waste in Covas. This paper discusses the share of energy use in the overall impact on the environment, employing different energy production schemes and taking into account diversification in the electricity production structure among EU countries.

\section{Materials and methods}

\subsection{Life cycle assessment methodology}

LCA is a structured, internationally standardized method and it is performed in four steps: 1) goal and scope, 2) life cycle inventory (LCI), 3) life cycle impact assessment (LCIA) and 4) interpretation. At the first stage the product or process is defined along with functional unit and the system boundaries. The functional unit is a quantitative description of the service performance, the system boundaries define the processes and the parts of the life cycle, which belong to the analysed system. Life Cycle Inventory (LCI) is a process of identifying and quantifying environmental exchanges: energy and raw materials consumption, emissions and other releases (to air, water and soil) and solid wastes for the entire life cycle of a product or process. The inputs and outputs of elementary flows that have been reported in the LCI are translated into impact indicator results related to three damage areas: human health, ecosystem and resource depletion in the LCIA stage. Interpretation occurs at every stage in an LCA [6].

Performing LCA for an innovative technology is a very complex task and it is usually done with a dedicated model and database. For the purpose of this study the LCA modelling was performed with SimaPro 8.3 software and Eco-invent database v.3.

As the method for LCIA, the ReCiPe was chosen. 17 impact categories are addressed at the midpoint level: Climate change Human Health, Ozone depletion, Human toxicity, Particulate matter formation, Ionising radiation, Photochemical oxidant formation, Climate change Ecosystems, Terrestrial acidification, Freshwater eutrophication, Terrestrial ecotoxicity, Freshwater ecotoxicity, Marine ecotoxicity, Agricultural land occupation, Urban land occupation, Natural land transformation, Metal depletion, Fossil depletion. At the endpoint level the midpoint impact categories are further converted and aggregated into the following three endpoint categories (damage categories): Damage to Human Health (HH), Damage to Ecosystem (ED) and Damage to Resource Availability (RA) [7]. 


\subsection{The system boundaries and functional unit}

The goals of this study are to identify environmental impacts of REE concentrate production from: tailings in New Kankberg and mining waste in Covas. The system boundaries include excavation and transport of secondary sources as well as beneficiation with disposal and land reclamation of the residues after beneficiation. The functional unit is defined as $1000 \mathrm{~kg}$ of a secondary source to be processed as the input for processes of REE recovery.

The system boundaries for REE concentrate production from New Kankberg tailings include transport of gold tailings to processing facility, followed by 3 stages of beneficiation: flotation, magnetic separation, filtration, then residues deposition and finally land reclamation.

The system boundaries for REE concentrate production from Covas include excavation and transport of old tailings to processing facility, 4 stages of beneficiation: size reduction and classification, gravimetric separation, magnetic separation, filtration, waste deposition and land reclamation.

\subsection{New Kankberg case}

The first secondary source of REE comes from Sweden - New Kankberg. New Kankberg is a gold mine, in which ore is mined underground and transported, around $10 \mathrm{~km}$, by truck to the concentrator. The ore is crushed and then gold is floated with tellurium. The gold is recovered by hot cyanide leaching from the flotation concentrate. The cyanide leaching residue is going to the tellurium plant. The tailings are going to the tailing pond.

In case of REE recovery from tailings, they will be directly pumped to a separate plant for further processing; therefore no excavating from a tailing pond is needed. The electricity consumption for transport by pipelines is assumed to be $0.2 \mathrm{kWh} / \mathrm{ton}$. The proposed beneficiation process for New Kankberg includes flotation and magnetic separation. Following the flotation stage, the concentrate that contains a mix of minerals (apatite and monazite) is further enriched through magnetic separation [8].

Electricity consumption for the whole beneficiation process for New Kankberg case is calculated in table 2 .

Table 2. Calculated energy consumption for beneficiation in New Kankberg [9]

\begin{tabular}{|c|c|c|c|}
\hline $\begin{array}{c}\text { Step of beneficiation } \\
\text { processes }\end{array}$ & $\begin{array}{c}\text { Unit energy consumption } \\
\text { per 1 ton of input material } \\
{[\mathrm{kWh} / \mathrm{Mg}]}\end{array}$ & $\begin{array}{c}\text { Mass of input material } \\
{[\mathrm{kg}]}\end{array}$ & $\begin{array}{c}\text { Calculated energy } \\
\text { consumption [kWh] }\end{array}$ \\
\hline Flotation & 5.0 & 1000 & 5.0000 \\
\hline Magnetic separation & 2.6 & 95.4 & 0.2480 \\
\hline $\begin{array}{c}\text { Dewatering } \\
\text { (concentrate) }\end{array}$ & 0.25 & 10 & 0.0025 \\
\hline Dewatering (residues) & 0.5 & 990 & 0.4950 \\
\hline
\end{tabular}

In the flotation process some chemicals are consumed: Water glass, Aero 845, Resinoline. After the beneficiation process residues go to the tailing pond to be disposed and then the land reclamation is foreseen.

\subsection{Covas case}

The second secondary source of REE comes from Portugal - Covas. The Covas tailings represents 30 years (1954-1984) of mining, exploited by underground mining works to 
produce tungsten. These tailings and the mining area were rehabilitated. 1 ton of tailings from Covas are excavated with a backhoe excavator, with fuel consumption of 18 litres. Then the tailings are sent by truck to a processing plant. It is assumed that processing plant will be located in a nearby area with $20 \mathrm{~km}$ distance.

The proposed beneficiation process of Covas tailings includes gravity separation and magnetic separation. After regrinding, tailings are reprocessed using a gravity separator.

This stage results in the production of a concentrate and tailings (residues). Later, the gravimetric concentrate is directed to magnetic separation producing a magnetic concentrate, a middling and non-magnetic tailings (residues), followed by dewatering (filtration) [8]. Electricity consumption for the whole beneficiation process for Covas case is calculated in table 3 .

Table 3. Calculated energy consumption for beneficiation in Covas [9]

\begin{tabular}{|c|c|c|c|}
\hline $\begin{array}{c}\text { Step of beneficiation } \\
\text { processes }\end{array}$ & $\begin{array}{c}\text { Unit energy consumption per } \\
1 \text { ton of input material } \\
{[\mathrm{kWh} / \mathrm{Mg}]}\end{array}$ & $\begin{array}{c}\text { Mass of input material } \\
{[\mathrm{kg}]}\end{array}$ & $\begin{array}{c}\text { Calculated energy } \\
\text { consumption }[\mathrm{kWh}]\end{array}$ \\
\hline $\begin{array}{c}\text { Size reduction }+ \\
\text { Classification }\end{array}$ & 15 & 1000 & 15 \\
\hline Gravity Separation & 0.5 & 1000 & 0.5 \\
\hline Magnetic separation & 2 & 184 & 0.368 \\
\hline Dewatering & 0.5 & 184 & 0.092 \\
\hline
\end{tabular}

The most suitable option for the residues after beneficiation process is the return to the disposal facilities they were taken from followed by reclamation. The beneficiation residues are useful for land reclamation; however the reclamation should include their neutralization due to high acidity and fertilization with organic amendments such as sewage sludge or compost [10].

\subsection{Energy sources scenarios}

For purposes of this study three scenarios are taken into consideration for each case. Each scenario applies different energy production scheme. Three exemplary production schemes are chosen based on the case locations. The energy schemes for Sweden, Portugal and average for Europe are applied. Energy production structures are based on official national statistical information including import/export, detailed, local power plant models. The inventory data is partly based on the primary industry data, measured at representative power plants, partly on the secondary literature data. The shares of electricity technologies on this market are valid for the year 2014. The source of the data is Ecoinvent v 3.0. database [11].

The hydropower has the biggest share in general electricity production in Sweden. It states for $32.21 \%$ of general national production and is divided into 2 sub-processes: reservoir (8.21\%), run-of-river (32.83\%). Second biggest share is nuclear power constituting $39.65 \%$ of produced energy. Two technologies are present in Swedish market boiling water reactor $(11.75 \%)$ and pressure water reactor $(27.90 \%)$. Around $9 \%$ of energy is imported to the country from Germany $(0.48 \%)$, Denmark $(2.05 \%)$, Norway $(6.41 \%)$ and Poland $(0.07 \%)$. Regarding the wind power $(7.23 \%)$ on shore and offshore power plants exist. The offshore turbines (1-3 MW) are responsible for $0.29 \%$ of electricity production. The contribution of onshore turbines $(<1-3 \mathrm{MW},<1 \mathrm{MW},>3 \mathrm{MW})$ is $6.94 \%$. The remaining energy is produced either with oil $(0.01 \%)$, peat $(0.13 \%)$ combustion or in heat power cogeneration systems $(2.93 \%)$ (using wood chips, oil, natural gas, hard coal, biogas in gas engine). The structure of electricity production in Sweden is shown in figure 1. 
In Sweden the hydropower has also biggest share in electricity production in Portugal. It states for $32.21 \%$ of general national production. In general 3 production technologies are included in this group: pump storage (1.67\%), reservoir $(10.38 \%)$ and run-of-river $(20.15 \%)$. Share of wind energy in general production of Portugal is $23.79 \%$. It includes onshore wind turbines <1MW (0.86\%), 1-3 MW (0.01\%), 1-3 MW (22.91\%). Another source with a significant share in the general electricity production is hard coal burning. $22.76 \%$ of Portuguese energy is produced accordingly. Part (14.38\%) of the energy used in Portugal is imported from Spain. The remaining sources are natural gas (3.07\%), oil (1.64\%), heat and power co-generation using oil $(0.37 \%)$ and heat and power co-generation using wood chips $(1.40 \%)$. The structure of electricity production in Portugal is shown in figure 2 .

\section{Electricity production in Sweden}

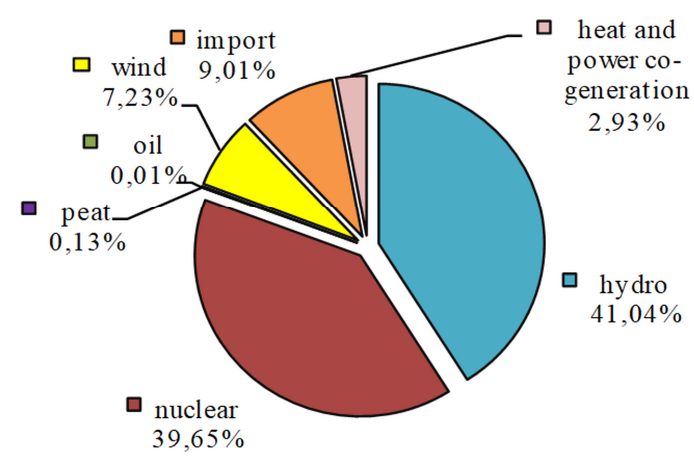

Fig. 1. Electricity production scheme in Sweden [12]

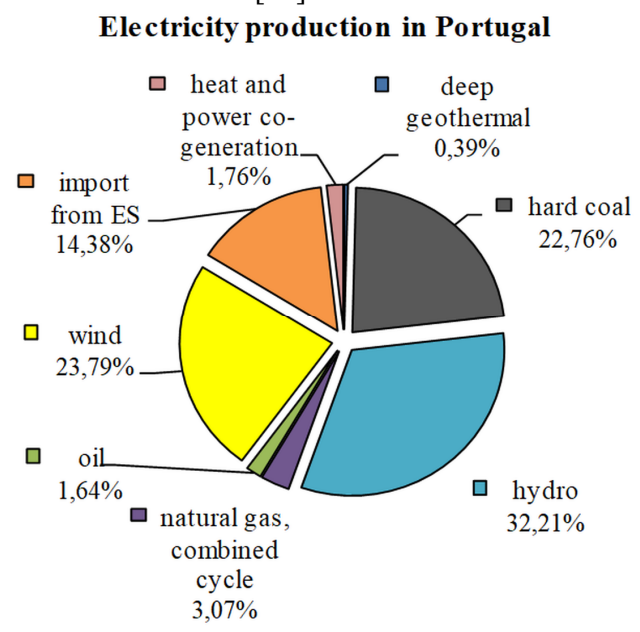

Fig. 2. Electricity production scheme in Portugal [12]

In addition to data on energy production for individual countries, Ecoinvent database includes larger, geographically relevant datasets, e.g. ENTSO-E - data on electricity production in European Network of Transmission System Operators, UCTE- data on energy production in Union for the Coordination of Transmission of Electricity. For this study ENTSO-E dataset was employed from Ecoinvent database. The share of individual countries in electricity production in Europe - ENTSO is shown in figure 3. 


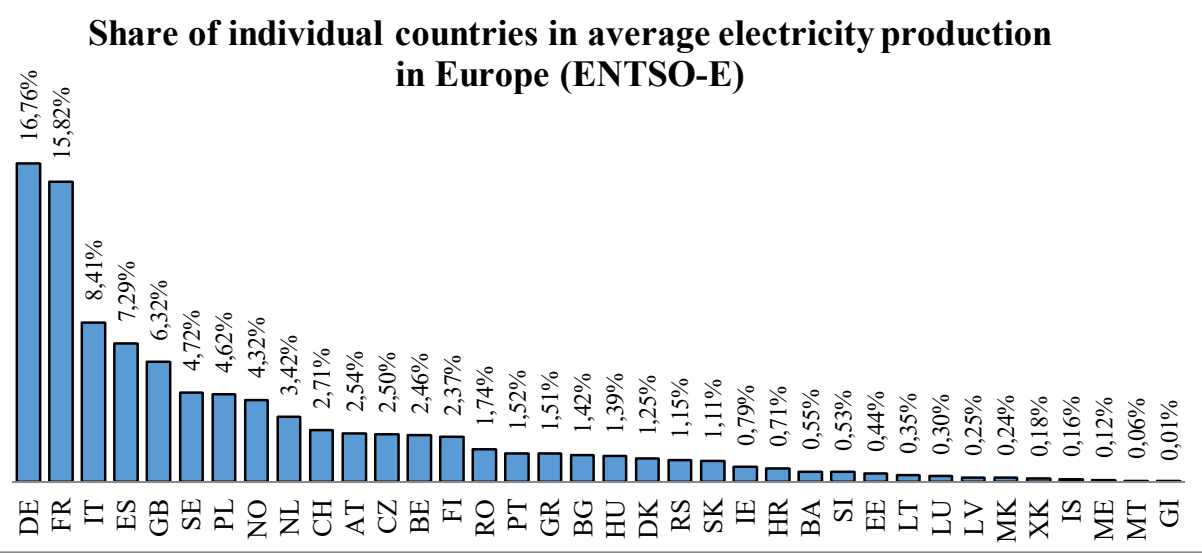

Fig. 3. Share of individual countries in average electricity production in Europe

This dataset includes the share of 36 individual country production in general production of a region and therefore is regarded to be average for Europe: Austria, Bosnia and Herzegovina, Belgium, Bulgaria, Switzerland, Czech Republic, Germany, Spain, France, Gibraltar, Greece, Croatia, Hungary, Italy, Luxembourg, Montenegro, Macedonia, Netherlands, Poland, Portugal, Romania, Serbia, Slovenia, Slovakia, Kosovo, Denmark, Estonia, Finland, Great Britain, Ireland, Iceland, Lithuania, Latvia, Malta, Norway, Sweden. The individual country shares are presented on picture above. The biggest contributors are: Germany (16.76\%), France (15.82\%) and Italy (8.41\%).

As mentioned, for both case studies of REE recovery from secondary sources various energy schemes are applied. All analysed scenarios are listed below:

- New Kankberg [SE]: The base scenario for New Kankberg case uses energy production scheme for Sweden. That means the energy used for production of REE concentrate in New Kankberg in this scenario is produced in Sweden.

- New Kankberg [PT]: In this scenario the energy production scheme for Sweden is substituted with energy production scheme for Portugal.

- New Kankberg [ENTSO-E]: In third scenario the average energy for Europe is applied instead of local energy production schemes.

- Covas [PT]: The medium voltage energy for Portugal is used in this scenario. The energy used for production of Covas concentrate in this scenario is produced in Portugal.

- Covas [SE]: The scenario employs energy production scheme for Sweden. Portuguese energy production scheme used in base scenario is replaced with Swedish energy production scheme. The other processes remain unchanged.

- Covas [ENTSO-E]: In third scenario the average energy for Europe is applied instead of local energy production schemes.

\section{Results and discussion}

\subsection{Results of modelling for New Kankberg}

The base scenario (New Kankberg [SE]) for New Kankberg REE concentrate production was analysed. The environmental impact is presented in 3 damage categories: Damage to Human Health, Damage to Ecosystems and Damage to Resources Availability (see fig. 4). The electricity use contributes to environmental impact in all categories. It is responsible respectively for $11.52 \%$ of Damage to Human Health indicator value, $7.42 \%$ of Damage to 
Ecosystems indicator value and $11.30 \%$ of Damage to Resources Availability category indicator value.

The environmental impact of REE concentrate production in New Kankberg for three scenarios is shown in figure 6. The lowest environmental impact in all damage categories is observed for initial New Kankberg [SE] scenario where energy production from Sweden is applied. After introducing energy production for Portugal (New Kankberg [PT] scenario) into the model the Damage to Human Health category indicator increased by $51 \%$, Damage to Ecosystems category indicator is higher by $15 \%$ and Damage to Resources Availability category indicator raised by $49 \%$. When the average European electricity production is used (New Kankberg [ENTSO-E] scenario), the further increase in environmental impact in all damage categories is observed.

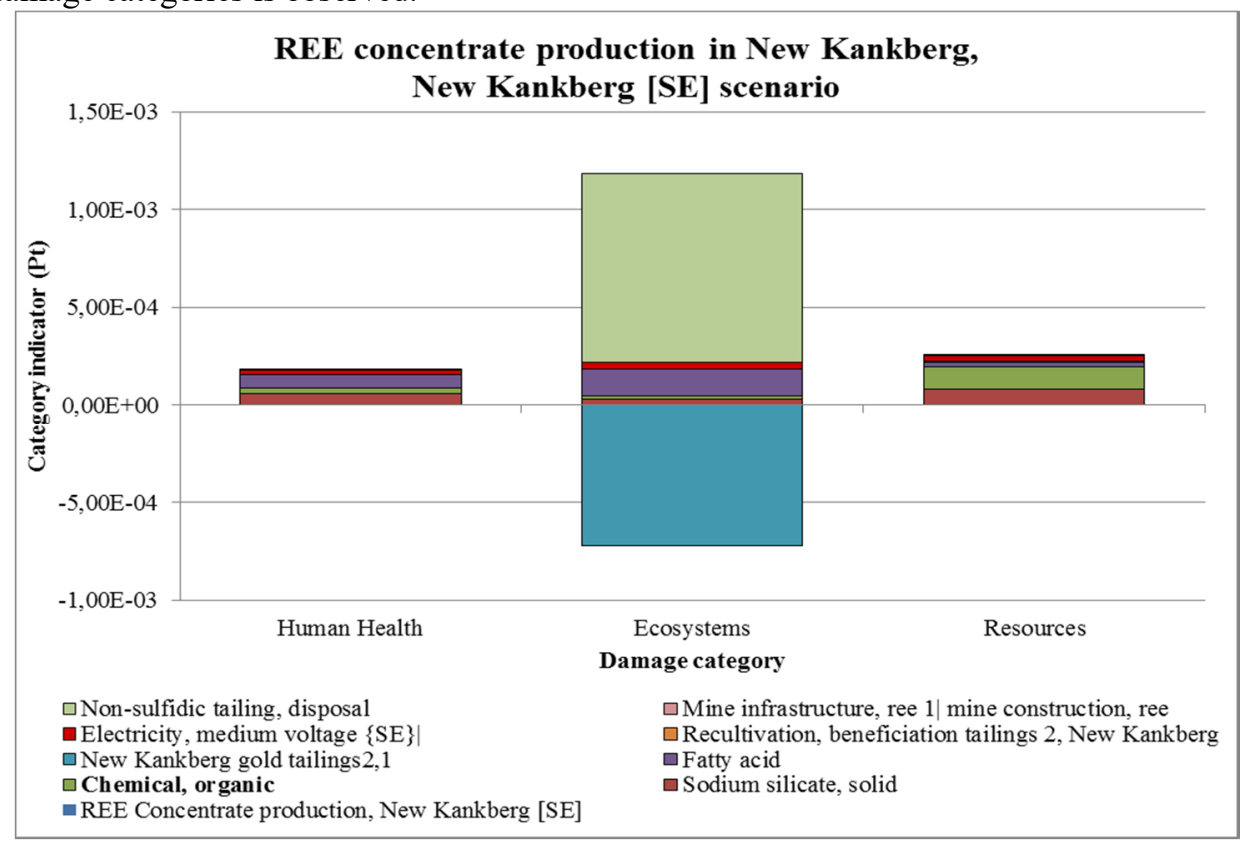

Fig. 4. LCA results for REE concentrate production in New Kankberg, New Kankberg [SE] scenario

\subsection{Results of modelling for Covas}

The base scenario (Covas [PT]) for Covas REE concentrate production was analysed. The environmental impact is presented in 3 damage categories: Damage to Human Health, Damage to Ecosystems, Damage to Resources Availability (see figure 5). The electricity use is significant contributor to environmental impact in all categories. It is responsible for respectively $37.94 \%$ of Resources Availability category indicator value, $42.58 \%$ of Damage to Ecosystems category indicator value and $44.04 \%$ of Damage to Human Health category indicator value.

The environmental impact of REE concentrate production in Covas for three scenarios is shown on figure 6 . The lowest environmental impact in all damage categories is observed for scenario where electricity produced in Sweden is applied. The Damage to Human Health category indicator decreased by $38 \%$, Damage to Ecosystems category indicator is lower by $29 \%$ and Damage to Resources Availability category indicator declined by $35 \%$. Comparing the initial scenario (PT) with average European electricity use, the Portuguese scenario has either equal environmental impact ( $\mathrm{HH}$ category) or slightly lower impact. The 
environmental impact indicator increased by $14.26 \%$ in Damage to Ecosystems category and respectively by $10 \%$ in Resources Availability category.

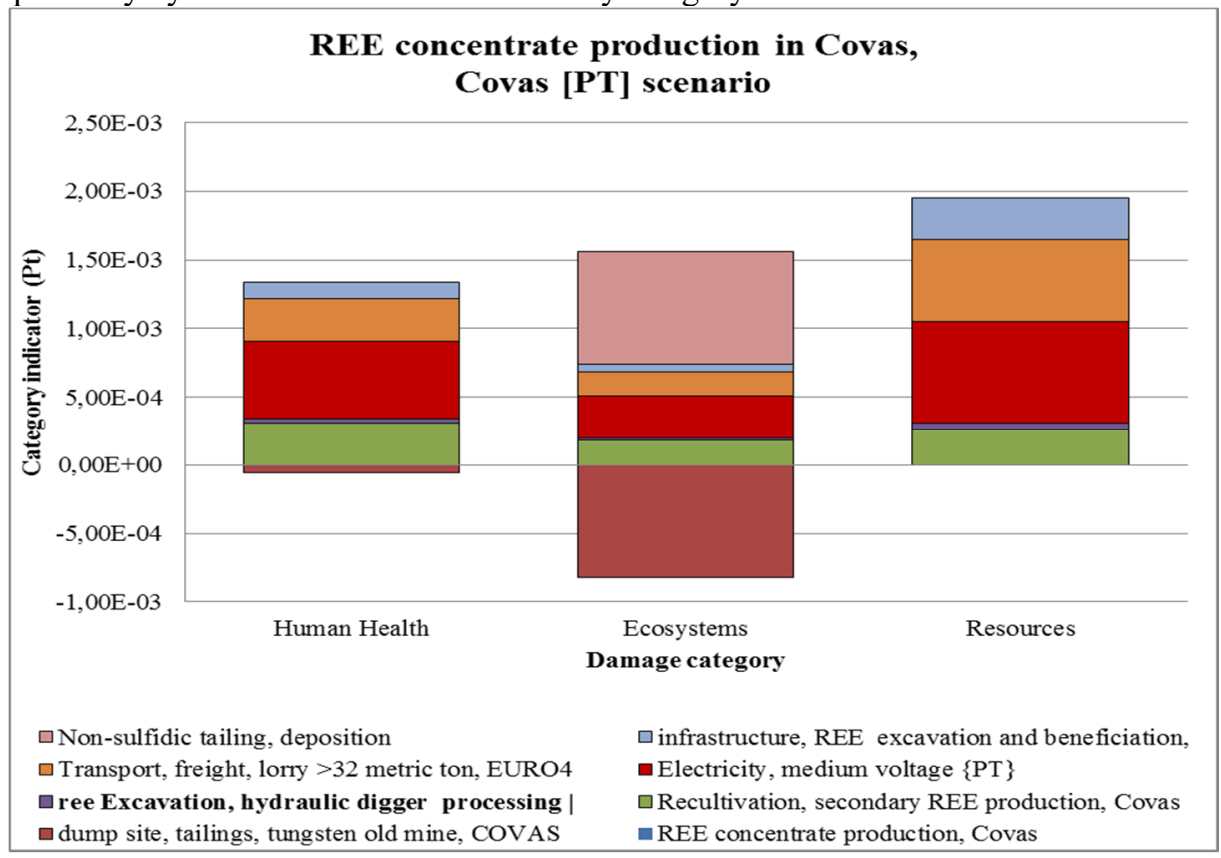

Fig. 5 . LCA results for REE concentrate production in Covas, Covas $[\mathrm{PT}]$ scenario

\subsection{The share of energy use in the overall impact on the environment}

The share in environmental impact of energy use differs significantly between scenarios employing diverse energy production schemes (fig.6).

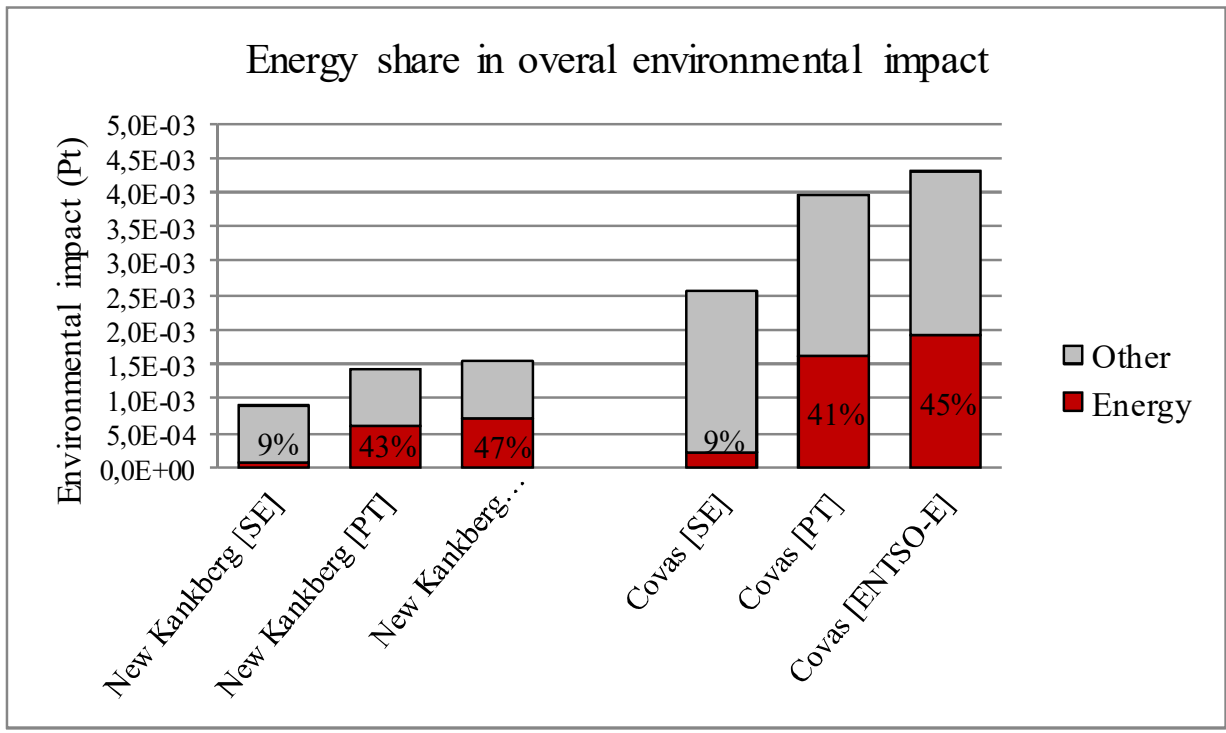

Fig. 6. Energy share in overall environmental impact of REE recovery, all scenarios 
The share in environmental impact of energy use differs significantly between scenarios employing diverse energy production schemes (fig.6). The lowest environmental impact and the lowest energy use share were observed for scenarios where Energy production scheme for Sweden was applied: New Kankberg [SE] and Covas [SE]. The energy use share in those scenarios equals $9 \%$ of overall impact on the environment. For the scenarios where energy production mix for Portugal is applied the overall shares of electricity use in environmental impact comes up to $43 \%$ for New Kankberg case and $41 \%$ for Covas case. The average European energy is applied in scenarios New Kankberg [ENTSO-E] and Covas [ENTSO-E]. Those scenarios have the highest negative impact on environment and are characterized by the biggest energy use contribution, accordingly $47 \%$ and $45 \%$ of environmental impact.

\section{Conclusions}

The study presents the differences in results of Life Cycle Assessment of REE recovery from mining waste in Covas and tailings in New Kankberg, resulting from use of various electricity production schemes for: Sweden, Portugal and average for Europe. The energy production in Sweden is based on hydro power and nuclear power. Whereas in Portugal main energy sources are hard coal combustion, hydro power and wind power. The technology lines of REE recovery in Covas and New Kankberg are diverse, as a result the demand for electricity necessary for processing of $1000 \mathrm{~kg}$ of secondary source material is different for each case study. Respectively the processing of tailings from New Kankberg requires 5.3 $\mathrm{kWh}$, while processing of mining waste from Covas requires $15.5 \mathrm{kWh}$.

For the REE concentrate production in New Kankberg (New Kankberg [SE], base scenario, electricity produced in Sweden) the share of energy production in the overall environmental impact is relatively low and equals $9 \%$. For New Kankberg case, when the local energy production scheme is substituted with Portuguese energy production or average energy for Europe the significant increase in the environmental impact is observed.

For the REE concentrate production in Covas (Covas [PT], base scenario, electricity produced in Portugal) the share of energy in the total environmental impact is high and equals $41 \%$. When the energy supply is changed into Swedish energy scheme (scenario Covas [SE]) the significant decrease in the environmental impact and energy share is observed. On the other hand when the average European electricity production is applied to Covas case (Covas [ENTSO-E] scenario) the slight increase in the negative effect on the environment is noticed.

The energy use is a significant contributor to the overall environmental impact of studied cases of rare earth elements recovery from secondary sources. Its share in the total environmental burden of the process is reaching up to $47 \%$. The share of energy production in environmental effect of the process depends on the processing technology used and its electricity demand. Moreover, it is closely related to the energy production structure used to supply this process. The results of this study show that applying the average electricity scheme production for Europe may lead to biased LCA results. For example, when the average European energy production scheme is implemented into New Kankberg model, the final environmental impact is significantly higher comparing to the scenario with local energy production. For the accurate LCA results the local production schemes of energy for certain countries should be chosen from databases.

Acknowledgements: This publication and research was funded by grant no 15.11.150.522 AGH University of Science and Technology, Faculty of Mining Surveying and Environmental Engineering. 


\section{References}

1. ENVIREE project web site. Basics on REE, http://www.enviree.eu/aboutenviree/basics-on-ree/ [acessed September 2018]

2. EURARE project web site. Uses of the Rare Earth Elements http://www.eurare.eu/RareEarthElements.html, [accessed September 2018]

3. European Commission, Report on Critical Raw Materials for the EU. Report of the Ad hoc Working Group on defining critical raw materials, (2014)

4. K. Grzesik, B. Bieda, R. Kozakiewicz and K. Kossakowska, Goal and scope and its evolution for Life Cycle Assessment of Rare Earth Elements recovery from secondary sources. SGEM 2017 Geoconference: energy and clean technologies 29 June-5 July, 2017, Albena, Bulgaria Vol. 17 iss. 41 Nuclear technologies recycling air pollution and climate change, 107-114, (2017)

5. K. Grzesik, K. Kossakowska, B. Bieda and R. Kozakiewicz R., Screening Life Cycle Assessment of beneficiation processes for Rare Earth Elements recovery from secondary sources. IOP EES: International Conference on the Sustainable Energy and Environmental Development, Poland (2017) - accepted manuscript

6. European Commission - Joint Research Centre - Institute for Environment and Sustainability, International Reference Life Cycle Data System (ILCD) Handbook General guide for Life Cycle Assessment - Detailed guidance. Publications Office of the European Union, (2010)

7. M. Goedkoop, R. Heijungs, M. Huijbregts, A. De Schryver, J. Struijs, R. van Zelm, ReCiPe 2008, A life cycle impact assessment method which comprises harmonised category indicators at the midpoint and the endpoint level First edition Report I: Characterisation; http://www.lcia-recipe.net

8. Y. Menard and A. Magnaldo, ENVIREE project, Deliverable D2.1: Report on the most suitable combined pretreatment, leaching and purification processes (2017),

9. K. Grzesi, K. Kossakowska, R. Kozakiewicz, B. Bieda, ENVIREE project, Deliverable D4.3 Environmental impact of the proposed beneficiation and separation processes (2018)

10. M. Chodak and T. Golda, ENVIREE project, Deliverable D4.2: Report on the proposed procedures and techniques for land reclamation (2017),

11. G. Wernet, C. Bauer, B. Steubing, J. Reinhard, E. Moreno-Ruiz and B. Weidema, The ecoinvent database version 3 (part I): overview and methodology. The International Journal of Life Cycle Assessment, [online] 21(9), 1218-1230 (2016), Available at: $<$ http://link.springer.com/10.1007/s11367-016-1087-8> [Accessed 09.09.2018]

12. IEA, IEA World Energy Statistics and Balances. OECD iLibrary, eISSN: 1683-4240, DOI: $10.1787 /$ enestats-data-en. (2017) 